\title{
Diurnally Asymmetric Trends of Temperature, Humidity, and Precipitation in Taiwan
}

\author{
CHEIN-JUNG SHIU \\ Research Center for Environmental Changes, Academia Sinica, Taipei, Taiwan \\ SHAW CHEN LIU \\ Research Center for Environmental Changes, Academia Sinica, and Institute of Atmospheric Sciences, \\ National Taiwan University, Taipei, Taiwan \\ JEN-PING CHEN \\ Institute of Atmospheric Sciences, National Taiwan University, Taipei, Taiwan
}

(Manuscript received 6 March 2008, in final form 4 June 2009)

\begin{abstract}
In this work, 45 years (1961-2005) of hourly meteorological data in Taiwan, including temperature, humidity, and precipitation, have been analyzed with emphasis on their diurnal asymmetries. A long-term decreasing trend for relative humidity $(\mathrm{RH})$ is found, and the trend is significantly greater in the nighttime than in the daytime, apparently resulting from a greater warming at night. The warming at night in three large urban centers is large enough to impact the average temperature trend in Taiwan significantly between 1910 and 2005. There is a decrease in the diurnal temperature range (DTR) that is largest in major urban areas, and it becomes smaller but does not disappear in smaller cities and offshore islands. The nighttime reduction in $\mathrm{RH}$ is likely the main cause of a significant reduction of fog events over Taiwan. The smaller but consistent reductions in DTR and RH in the three off-coast islands suggests that, in addition to local land use changes, a regional-scale process such as the indirect effect of anthropogenic aerosols may also contribute to these trends. A reduction in light precipitation $\left(<4 \mathrm{~mm} \mathrm{~h}^{-1}\right)$ and an increase in heavy precipitation $\left(>10 \mathrm{~mm} \mathrm{~h}^{-1}\right)$ are found over Taiwan and the offshore islands. The changes in precipitation are similar to the changes of other areas in Asia, but they are different from those of the United States, Europe, and the tropical oceans. The latter do not show any reduction in light precipitation.
\end{abstract}

\section{Introduction}

In one of our earlier works (Liu et al. 2002), we found that sunshine duration over Taiwan decreased by more than $15 \%$ since 1970 , which we attributed to an increase in either regional cloud cover or cloud albedo as a result of the indirect effect of increasing anthropogenic aerosols (in this work, by the word "regional" we mean a scale that is significantly greater than that of Taiwan, e.g., a synoptic or East Asian scale). The reduction in sunshine duration can lead to a reduction in daytime temperature. In addition, the increase in clouds or cloud albedo can increase nighttime surface temperature by

Corresponding author address: Dr. Shaw Chen Liu, Research Center for Environmental Changes, P.O. Box 1-48, Nankang, Taipei 115, Taiwan.

E-mail: shawliu@rcec.sinica.edu.tw trapping longwave radiation (e.g., Hansen et al. 1995). Thus, the net effect of increasing cloudiness or cloud albedo is a decrease in diurnal temperature range (DTR). Decreases in DTR have been observed worldwide, but the exact cause of the DTR trends is not well understood. Changes in cloudiness, aerosol scattering, urbanization (urban heat island), and atmospheric water vapor content have been suggested as potential causes (Karl et al. 1993; Eastering et al. 1997; Campbell and Vonder Haar 1997; Dai et al. 1999; Durre and Wallace 2001a; Hansen et al. 1995; Stenchikov and Robock 1995). The evapotranspiration cooling of plant physiological responses resulting from land use changes has been proposed as another possible cause, because of its influence on the daytime air temperature (Collatz et al. 2000; Durre and Wallace 2001b; Stone and Weaver 2002). The change of evapotranspiration is also a major cause of the urban heat island effect, which is known to be more pronounced 
at night than in the day. Other factors that contribute to the urban heat island effect include thermal radiation blocking of buildings, changes in the thermal properties of surface materials in urban areas, and extra heat release from utility and transportation sectors (Oke 1982; Arnfield 2003).

Taiwan is located at the southeastern rim of East Asia where emissions of air pollutants have been increasing drastically in the past few decades. Taiwan itself also experienced an extraordinary rapid economic development in the last four decades. As a matter of fact, both the current energy use and emissions of air pollutants per unit area in Taiwan are among the highest values found worldwide. While the rapid buildup of high concentrations of air pollutants and land use changes in Taiwan pose serious environmental problems, the high levels and their large dynamic ranges of changes over a short time provide an excellent opportunity for examining possible impacts on the regional versus local climate changes. In this work, we will look for the possible impacts of anthropogenic aerosols and land use changes. We will focus on the diurnally asymmetric changes of meteorological parameters because both aerosols and land use changes tend to have strong diurnal contrasts in their impacts.

\section{Data}

Forty-five years (1961-2005) of hourly measurements of specific humidity $(q)$, temperature $(T)$, relative humidity (RH), and precipitation are used. Figure 1 shows the locations of the 26 measurement stations operated by the Central Weather Bureau (CWB) in Taiwan, among which 18 of them have complete records back to 1961, 6 of which (viz., Taipei, Taichung, Tainan, Hualien, Taitung, and Hengchun stations) have records further back to 1911. Before 1961 the observation time interval was too coarse for the analysis of diurnal variations. Moreover, there is a difference in the frequency of observations at different stations; stations in Taipei, Taichung, Tainan, Hualien, and Taitung have hourly observations, but stations in Tamshui, Hsinchu, Jiyehtan, Alishan, Yushan, Hengchun, Keelung, Ilan, Chengkung, Tawu, Pengchiayu, Penghu, and Lanyu have only hourly observations at 0200, 0500, 0800, 0900, 1100, 1400, 1700, 2000, 2100, and 2300 LT. For the analysis of geographic variations, these stations are classified into the following three categories: sites located in low-elevation areas (denoted with stars), elevated stations (triangles), and three offshore stations (circles).

Among the low-elevation stations, Taipei, Taichung, and Tainan are major urban centers with populations over one million; whereas Hsinchu, Tamshui, Keelung,

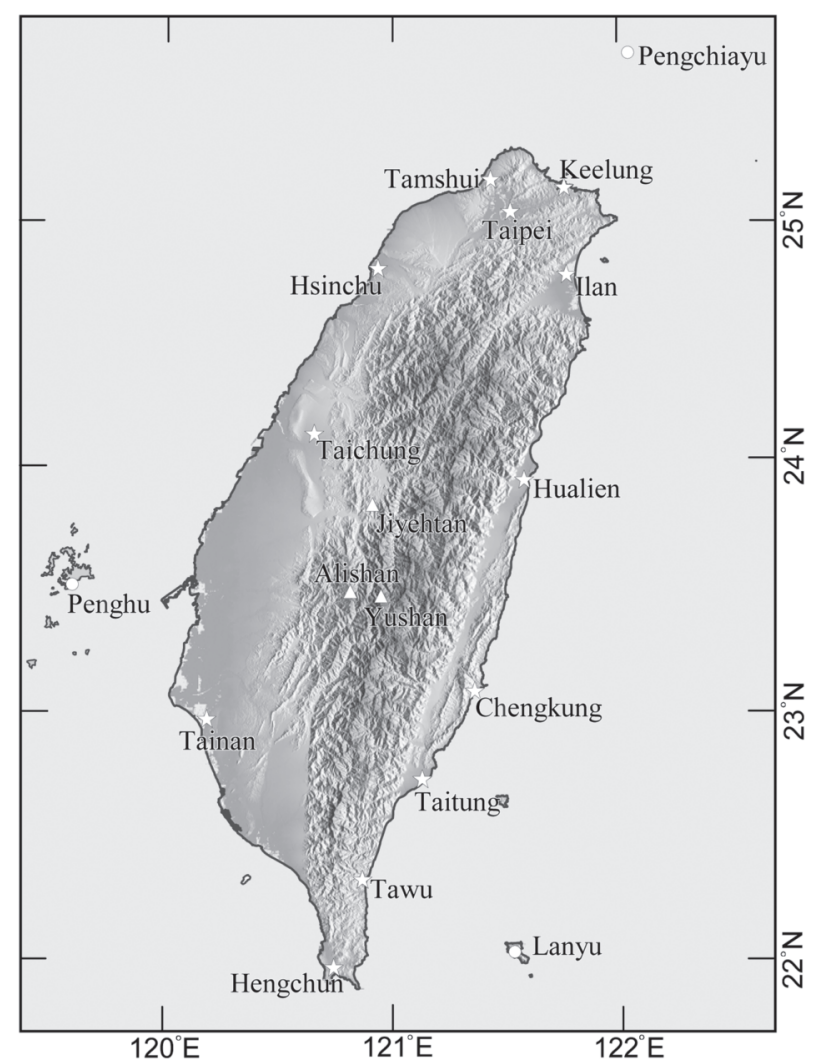

FIG. 1. Locations of meteorological stations in and around Taiwan used in this study. The shading denotes the elevation of terrain. A detailed description of stations is given in the text.

and Ilan are smaller cities in northern and northeastern Taiwan. The lack of any significant amount of flat land and the obstruction of transportation by the high Central Mountain Range (with averages of $2.5 \mathrm{~km}$ in elevation) prevent major industrial or urban development in the eastern part of Taiwan. Therefore, eastern stations (e.g., Hualien and Taitung) are influenced much less by anthropogenic activities compared to those in western Taiwan. This is demonstrated by the distribution of particulate matter less than $2.5 \mu \mathrm{m}$ in diameter (PM2.5) in Fig. 2, which shows a factor-of-2 less concentration in Hualien than that in western Taiwan. Another relatively clean station is Hengchun, which is located at the southern tip of Taiwan. Jiyehtan, Alishan, and Yushan are located in the Central Mountain Range with elevations of 1.0, 2.5 , and $3.8 \mathrm{~km}$, respectively. These stations, and Yushan in particular, have little human influence in close proximity. Of course, the three offshore stations (Pengchiayu, Penghu, and Lanyu) are also remote to any significant direct air pollution. In particular, Pengchiayu is uninhabited, whereas Lanyu station is on top of the highest hill (325 m) in the small, sparsely inhabited island. Moreover, being in the southeastern edge of all of the stations, Lanyu 


\section{PM2.5 in Taiwan (2004)}

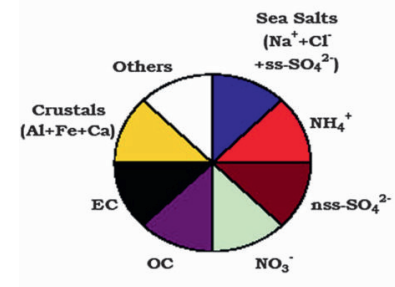

Unit: $\mu \mathrm{gm}^{-3}$

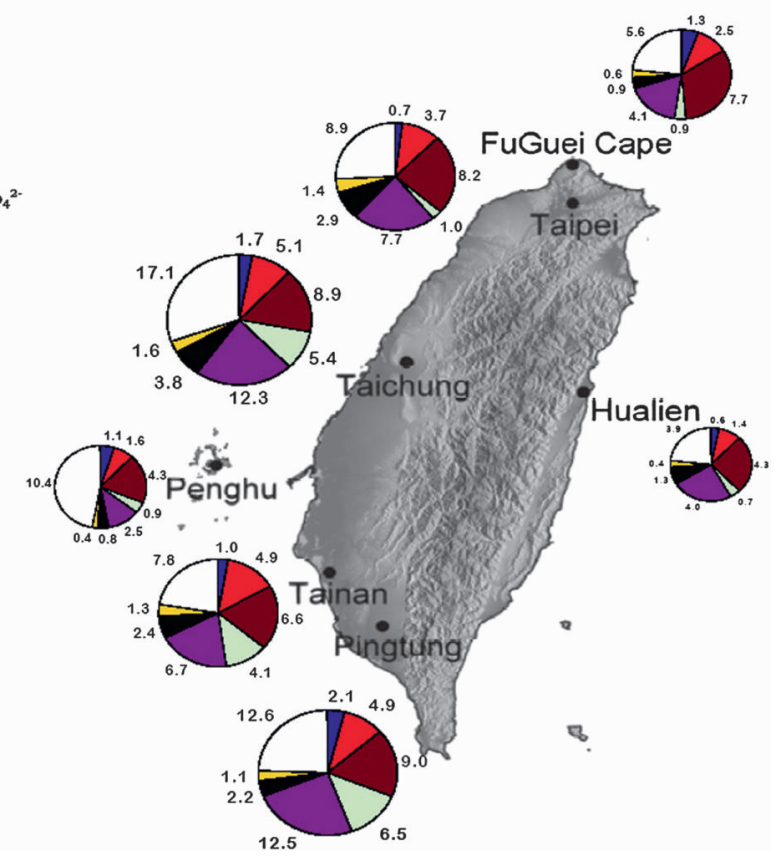

FIG. 2. Yearly average concentrations and chemical compositions of PM2.5 measured in 2004 at the seven stations in Taiwan. The measurements were made 1 week month ${ }^{-1}$.

is the most remote from the northeasterly monsoon that blows Asian continental pollutants toward Taiwan (e.g., Lin et al. 2004). Satellite images from the Moderate Resolution Imaging Spectroradiometer (MODIS) and Sea-viewing Wide Field-of-view Sensor (SeaWiFs) instruments show that aerosols from the Asian continent, such as Asian dust storms, which can significantly affect Pengchiayu to the north and Penghu to the west of Taiwan, often miss Lanyu. However, Lanyu is not entirely free from pollution sources because it is near the major shipping lane between Northeast Asia and Southeast Asia and beyond (Corbett et al. 2007; Eyring et al. 2005). Model simulations by Corbett et al. (2007) showed that ship emissions could contribute to about $0.5 \mu \mathrm{g} \mathrm{m}^{-3}$ to the average PM2.5 concentration near Lanyu. Nevertheless, this is about two orders of magnitude less than typical urban PM2.5 concentrations, and about a factor of 10 less than typical rural values in Taiwan.

One of the concerns is the inhomogeneities/biases caused by instrument changes and station relocation. We have checked the consistency of specific humidity, temperature, and relative humidity between adjacent stations and found negligible inhomogeneities around the time of relocation/instrument change. In addition, during the change of instruments, new instruments were always compared to the old ones side by side for a finite length of time to verify the consistency between them. In regard to the possible inhomogeneities caused by relocated stations, there have been four relocations among the 18 stations. One of the four relocated stations was moved for about 2 yr temporarily, and then moved back to the original location. The other three relocated stations only moved a small distance from their original locations. Thus, the inhomogeneities caused by the station relocation should be negligible.

To compare local temperature change in Taiwan to that resulting from regional- and global-scale warming, three additional temperature datasets are analyzed. The first, the Climate Research Unit (CRU) land air temperature anomalies on a $5^{\circ} \times 5^{\circ}$ gridbox basis (CRUTEM3), is a product of the Met Office's Hadley Centre and the CRU at the University of East Anglia (Brohan et al. 2006; Jones et al. 1999). It is a grid dataset of global historical land surface temperature anomalies, which contains monthly data since January 1850 on a $5^{\circ}$ grid. The second dataset is the Met Office Historical Night Marine Air Temperature Anomalies (MOHMATN4), which are monthly averages on $5^{\circ}$ grids from 1856 to the present (Parker et al. 1995). We also consider the Hadley Centre Global Sea Ice and Sea Surface Temperature dataset that gives monthly sea surface temperature (SST) in $1^{\circ}$ grids (HadISST_1.1_SST) from 1870 to the present (Rayner et al. 2003, 2006). For nighttime marine air 


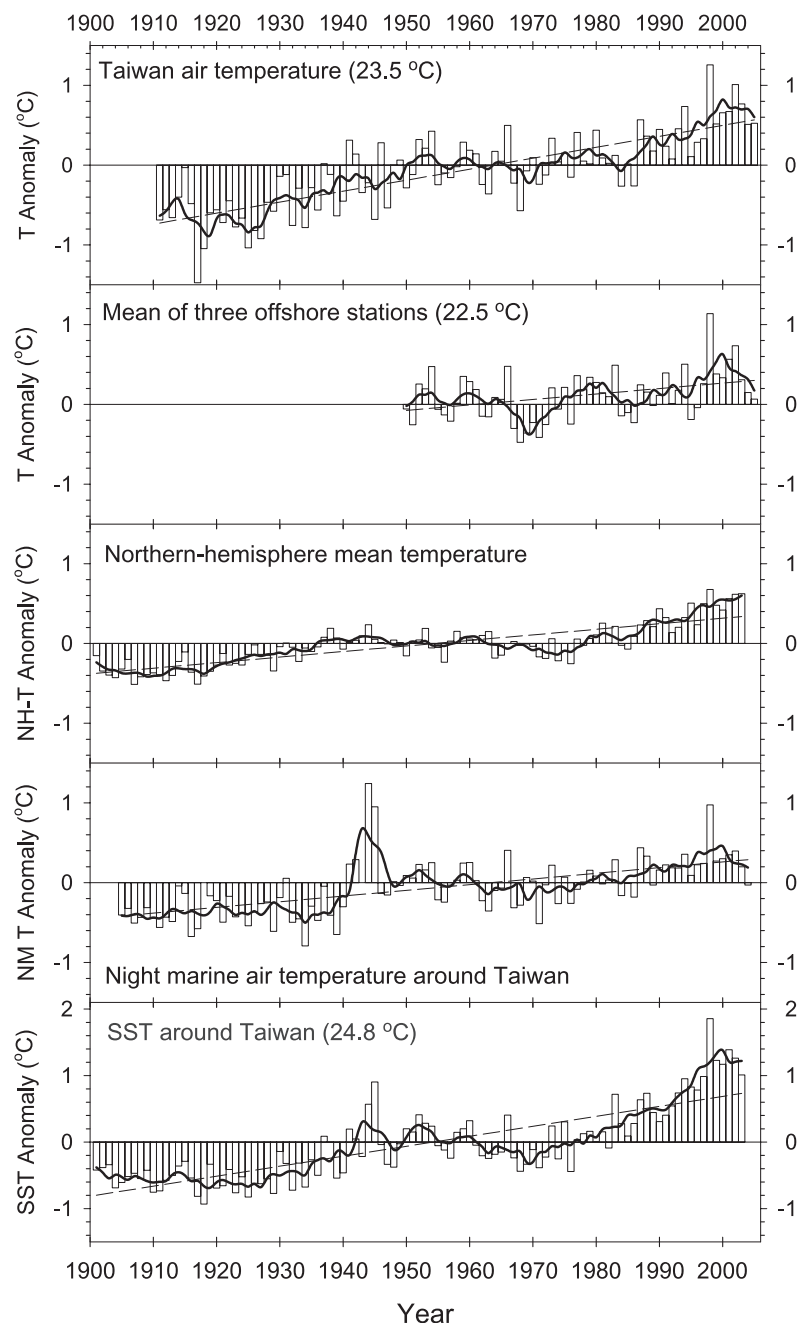

FIG. 3. (from top to bottom) The anomaly (deviation from the mean) of the average yearly temperature at the six long-term stations from 1911 to 2005, the anomaly of three offshore islands, the anomaly of average temperature for the entire Northern Hemisphere, the anomaly of nighttime sea surface air temperature around Taiwan, and the anomaly of sea surface temperature around Taiwan.

temperature and sea surface temperature, we use data in the six $5^{\circ} \times 5^{\circ}$ and twenty-three $1^{\circ} \times 1^{\circ}$ grids around Taiwan to represent the regional change, respectively.

The precipitation intensity data are obtained from daily precipitation amounts $(\mathrm{mm})$ divided by daily precipitation hours (h) recorded by the CWB in Taiwan from 1961 to 2005.

\section{Results and discussion}

\section{a. Temperature changes in and around Taiwan}

The top panel of Fig. 3 shows the anomaly (i.e., deviation from the mean of 1950-70) of annual mean temperature at the six long-term stations from 1911 to
2005. For comparison, the anomaly of the average temperature for the entire Northern Hemisphere (NH), the anomaly of the nighttime marine air temperature around Taiwan as mentioned in the last section, and the anomaly of the sea surface temperature around Taiwan are shown in the subsequent panels. It is obvious that the four profiles share substantial similarities in both general patterns and magnitudes. The most prominent similarity is the temperature increase from about 1920 to 1945 , which stayed near constant from about 1945 to 1975, and then increased persistently from about 1975 to 2000. The similarities suggest that the air temperature in Taiwan and the nighttime air and surface temperatures of the surrounding oceans are closely related to (or part of) global warming. However, one can also notice that the air temperature in Taiwan has warmed up by $\sim 1.4^{\circ} \mathrm{C}$ (linear regression) from 1911 to 2005 , which is about twice as fast as the $\mathrm{NH}$ air temperature $\left(\sim 0.7^{\circ} \mathrm{C}\right)$, whereas the nighttime sea surface air temperature around Taiwan has also warmed up by $\sim 0.7^{\circ} \mathrm{C}$. On the other hand, the sea surface temperature around Taiwan has warmed up by $1.5^{\circ} \mathrm{C}$. The reasons for the different and inconsistent magnitudes of the warming trends are not well understood. Hsu and Chen (2002) suggested that the stronger temperature increase over Taiwan than the global value could be due to fluctuations in large-scale circulation. Liu et al. (2002) suggested that local- and/or regional-scale effects, including the radiative effects of aerosols and land use changes, could be possible causes too. In this context, we notice that the average temperature increase at offshore stations, about $0.45^{\circ} \mathrm{C}$ from 1960 to 2005 , are consistent with the trend of nighttime sea surface air temperature around Taiwan, and more in line with the $\mathrm{NH}$ trend. Moreover, temperature increases at offshore stations over the past four decades are consistent with the increasing trends of temperature of about $0.1^{\circ} \mathrm{C}$ decade $^{-1}$ in southern China (Qian and Qin 2006). In contrast, the average increase over Taiwan's main island is about twice the temperature increase at offshore stations, suggesting that the higher temperature trend in Taiwan could be due to local effects, such as the urban heat island effect. Aerosols may also contribute to the local effects in the form of warming at nighttime and cooling in the daytime. Figure 4 compares the average temperature trends of the 3 largest urban stations (Taipei, Taichung, and Tainan) to that of the other 11 stations, including 8 medium-sized urban stations (Tamshui, Hsinchu, Keelung, Hualien, Taitung, Chengkung, Tawu, and Hengchun), and 3 offshore stations (Pengchiayu, Penghu, and Lanyu). The influence of the urban heat island effect is obvious. Population growth in 1961-2005 in the three large urban centers of Taipei, Taichung, and Tainan is about threefold. The area of the 


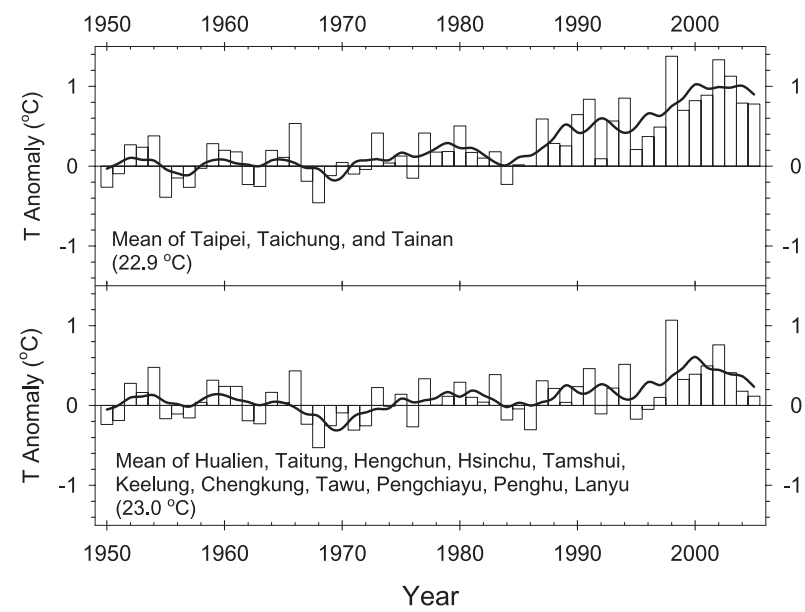

FIG. 4. The anomaly of average yearly temperature at (top) Taipei, Taichung, and Tainan stations and (bottom) the other 11 stations from 1950 to 2005.

three large cities increases even more, by about 4 times. In comparison, population growth in smaller cities and rural areas is only about $80 \%$. Trends of aerosols follow a similar spatial pattern. Figure 5 depicts linear trends of the annual sunshine hours at individual stations. Sunshine hours are a measure of direct solar radiation. They are inversely proportional to the column density of aerosols. Unfortunately, the column density of aerosols can not be derived from the sunshine hours because the sunshine hours are also strongly affected by clouds. What we can conclude is that the local, not the regional, effect is the major contributor to the greater temperature trend in Taiwan relative to the $\mathrm{NH}$ average.

Thus far our analysis has focused on the linear trend and neglects shorter-term variabilities such as those resulting from ENSO or decadal processes. Our approach could cause an overestimation of the statistical significance, and/or even misinterpret the dynamical or other physical processes (Jones 1989; Bloomfield 1992). To address the possible overestimation of the statistical significance of the trends, we have applied the PraisWinsten estimates (Prais and Winsten 1954; Choudhury et al. 1999) in the trend analysis to remove the autocorrelation and to estimate true regression coefficients from the time series with first-order autocorrelated errors. Such an autoregression procedure allows us to remove the autocorrelation inherent in different time series and ascertain any statistically significant relationships between dependent variables and candidate regressors. This autoregression procedure is somewhat similar to the procedures used in Zheng et al. (1997). We have evaluated the difference of the values of trends between the simple linear regression and the autoregression procedure applied in this study. For those trends that are

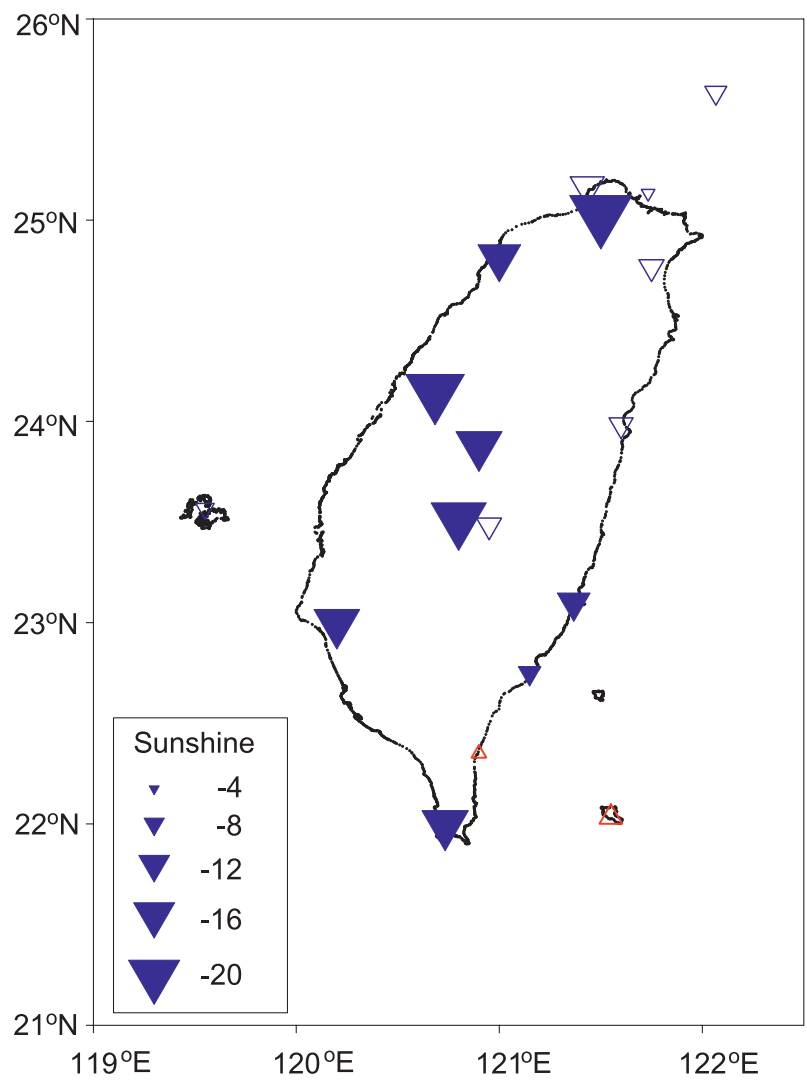

FIG. 5. Linear trends of sunshine hours. Positive (upwardpointing triangles, red) and negative (downward-pointing triangles, blue) trends are denoted. Magnitudes of trends are proportional to the size of triangles $\left[\%(4 \text { decades })^{-1}\right]$. Filled triangles indicate statistical significance at the $95 \%$ confidence level.

statistically significant, the effect of applying the autoregression procedure is less than $10 \%$ (mostly 5\%). For trends that are not statistically significant, the effects of applying the new procedure can be as large as $50 \%$. However, this has little impact on the discussion because it does not change the fact that the trends are not statistically significant.

\section{b. Diurnal temperature changes and humidity}

The long-term trends of annual and seasonal averages of the three meteorological parameters ( $T, q$, and $\mathrm{RH})$ at the Taipei station for the daytime and nighttime hours are shown in Figs. 6a,b, respectively. Also shown are the 5 -yr running averages. The mean daytime $T$ at the Taipei station had significant variability but no obvious longterm linear trend from 1961 to 2005 . The same is true for $q$ and RH. In contrast, a positive trend in $T$ and a negative trend in RH clearly stand out in the nighttime profiles (see also Table 1) for all seasons. Similar patterns can also be found in other major urban centers (e.g., Taichung and Tainan, not shown), as well as medium-sized cities 
(a)
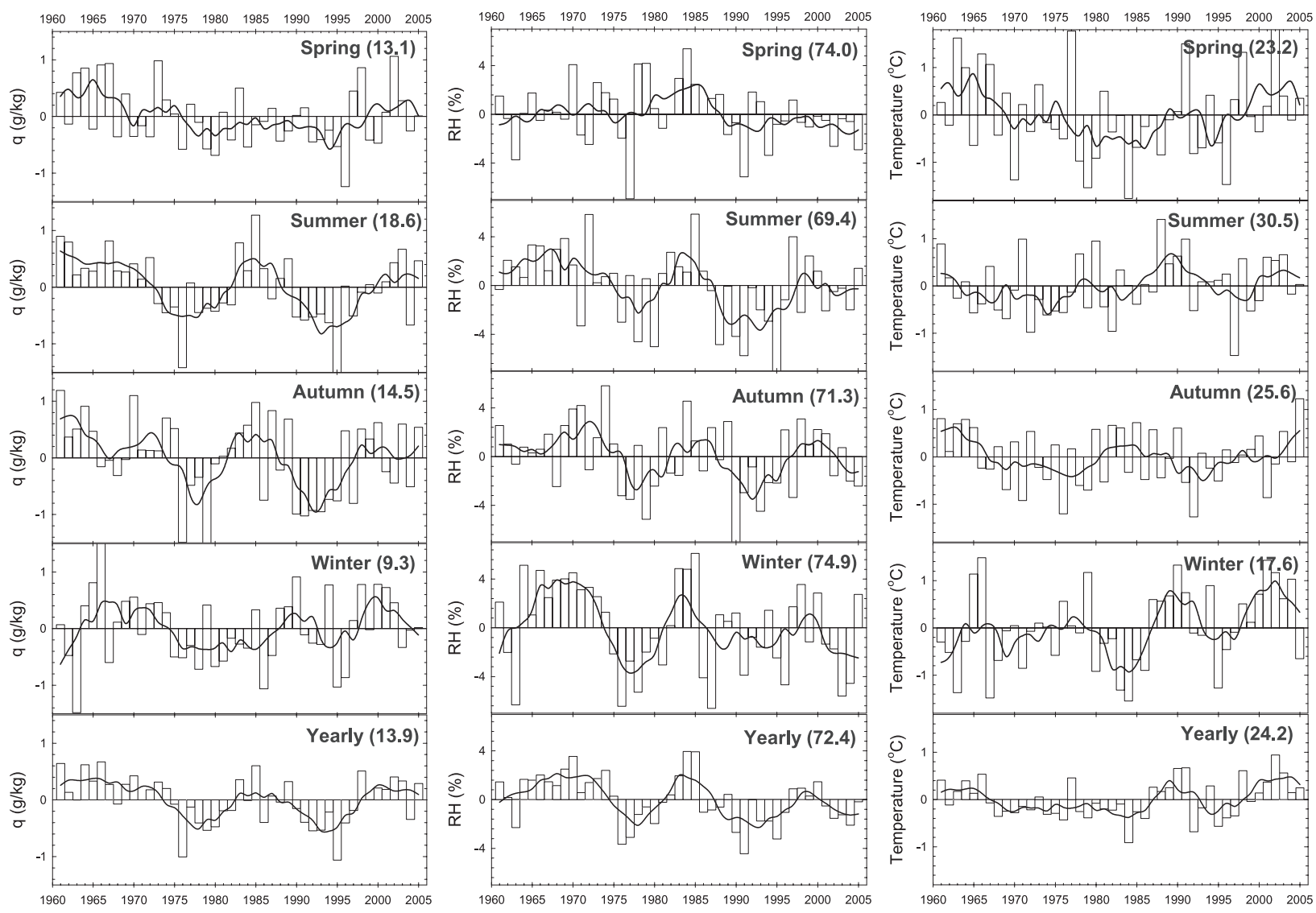

FIG. 6. Annual and seasonal variations of meteorological parameters at the Taipei station for (a) daytime and (b) nighttime: (left) specific humidity, (middle) relative humidity, and (right) temperature. Also shown are the 5-yr running average profiles. The mean values are shown in the parentheses.

(e.g., Hsinchu, Jiyehtan, and Hengchun, not shown). Even the mountain station of Alishan (with an altitude of about $2.5 \mathrm{~km}$ ) exhibited similar features (not shown). The trends also exist but are less obvious in stations over eastern Taiwan. This is the case even at the two offshore stations of Pengchiayu and Penghu. In fact, only Lanyu, the most remote offshore station, shows daytime variations similar to those of the nighttime (not shown). Even so, the daytime temperature at Lanyu started to lag the temperature increase in the nighttime after about 1990. In summary, the diurnally asymmetric trends of $q$, RH, and $T$ are largest in major urban areas in the main island of Taiwan, then become smaller in smaller cities and offshore islands, and finally minimize (but not disappear) in Lanyu, the most remote offshore island.

Using the linear regression analysis and taking account of serial correlation in the time series as mentioned in section $3 \mathrm{a}$, we have calculated the magnitudes of the trends during the four and a half decades for 18 stations that have full records back to 1961 . The geographical distributions and magnitudes of the trends at each station are displayed in Fig. 7 and Table 1. Trends of nighttime air temperature are most obvious, showing strong warming for most of the stations on the main island. Daytime temperature change is much smaller, and a few urban stations located in the western plain even showed some declines. There are significant decreases of daytime specific humidity in most stations in Taiwan's main island during summer, but not at the offshore stations, high mountain stations, or in winter. Because the RH is closely related to both $q$ and $T$, the above changes lead to its different trends in the daytime versus the nighttime. During daytime, the effects from the changes of $q$ and $T$ are small, with some even offsetting each other, such that the trends in $\mathrm{RH}$ are negligible. However, during the night, the warming trend is so overwhelming that most of the main island stations experienced reductions of relative humidity. Such trends are not seen over the offshore islands because of the offsetting changes in $q$ and $T$. 
(b)
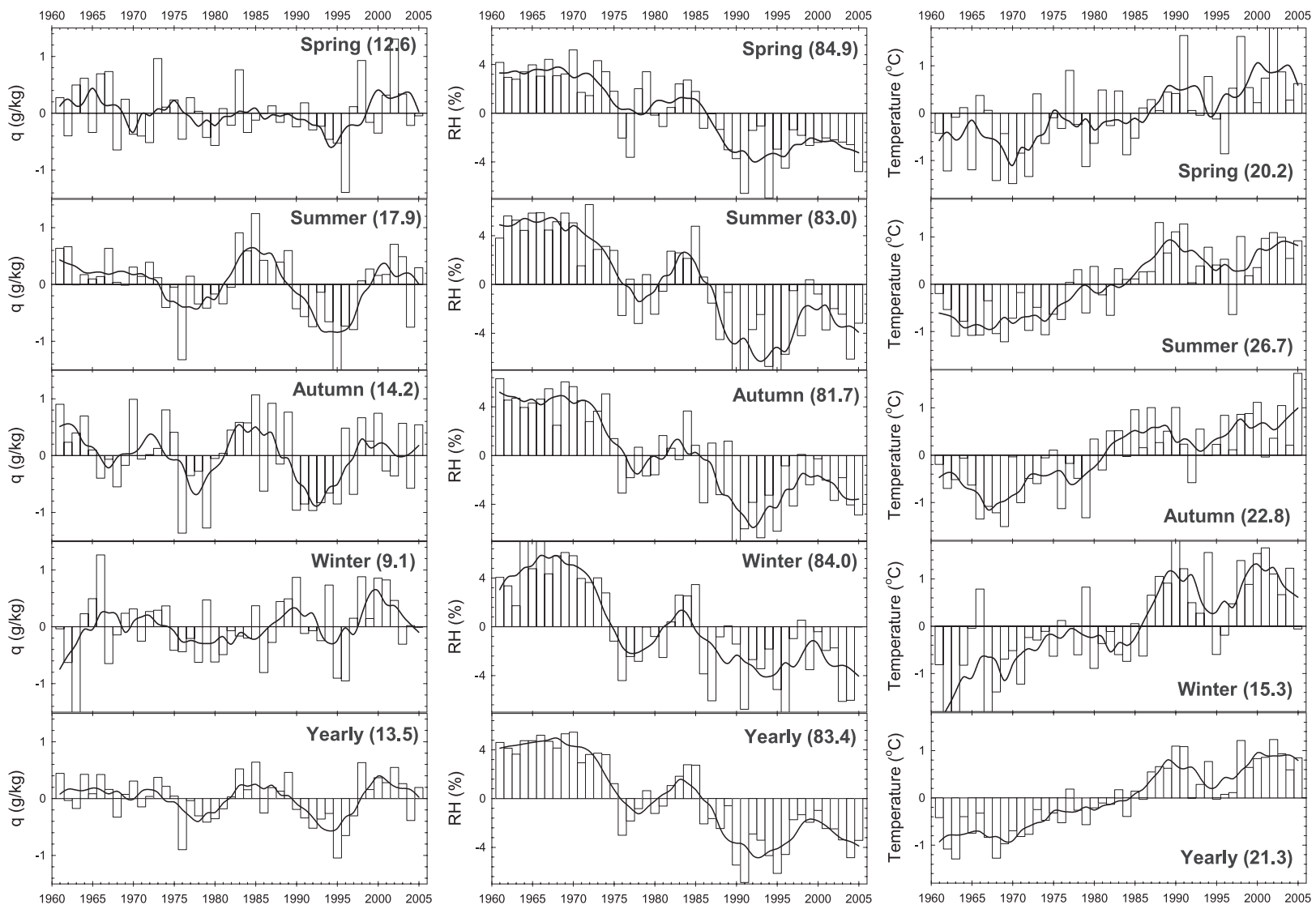

FIG. 6. (Continued)

We can summarize the major features of the analysis thus far in section $3 \mathrm{~b}$ as follows. 1) There are significant nighttime warming trends at all stations in both summer and winter. The trends are clearly proportional to the degree of urbanization, but have a regional background value because the value at an uninhabited offshore island is similar to those at relatively clean rural stations in Taiwan's main island (see also Table 2). Obviously, the significant nighttime warming trends are the result of the following three forcings: the global greenhouse, the urban heat island, and aerosols, all of which work in the same direction, that is, toward increased warming. 2) Temperature changes during daytime are small at all stations and some even show significant negative trends, suggesting that the cooling effect of aerosols in daytime is large enough to cancel the warming because of the urban heat island effect and global greenhouse effect. This finding and that of the first feature should provide a good constraint for a comprehensive modeling study of regional climate changes. 3) Significant declines of summertime specific humidity have occurred over Taiwan's main island for both day and night, but there are no such trends in winter or over the offshore islands; however, some offshore islands show slight increases in the specific humidity. 4) Significant decreases of nighttime RH over Taiwan's main island have occurred all yearround, which are mainly caused by the nighttime warming trends; a decrease in $q$ plays a minor role, but only during summer.

In regard to the trend in specific humidity, we note that tropospheric warming increases the atmospheric waterholding capacity exponentially by about $7 \% \mathrm{~K}^{-1}$, according to the Clausius-Clapeyron equation (Trenberth 1998; Allen and Ingram 2002). It is usually assumed in the climate models that the RH remains approximately constant during climate warming or cooling. This is supported by the available observations (e.g., Soden et al. 2002; Dai 2006; Solomon et al. 2007). However, trends of $q$ and $T$ for most of the stations in Taiwan's main island are opposite to each other (Fig. 7 and Table 1). This is puzzling because, being an island, the atmospheric moisture in Taiwan is most frequently brought over from the oceans around Taiwan. A reduction in moisture could happen if the land-sea breeze would be weakened by 
TABLE 1 . Trends of specific humidity $(q)$, temperature $(T)$, and relative humidity (RH) over four decades (1961-2005) are shown for the daytime and nighttime. Trends in bold represent statistical significance above the $95 \%$ confidence level.

\begin{tabular}{lccc}
\hline \hline & $q\left[\mathrm{~g} \mathrm{~kg}^{-1}\right.$ & $T\left[{ }^{\circ} \mathrm{C}\right.$ & $\mathrm{RH}[\%$ \\
Daytime & $\left.(4 \text { decades })^{-1}\right]$ & $\left.(4 \text { decades })^{-1}\right]$ & $\left.(4 \text { decades })^{-1}\right]$ \\
\hline Taipei & -0.31 & 0.20 & -2.06 \\
Taichung & $-\mathbf{0 . 7 2}$ & 0.06 & $-\mathbf{3 . 2 8}$ \\
Tainan & -0.39 & -0.29 & 0.21 \\
Hsinchu & $-\mathbf{0 . 7 4}$ & -0.26 & $-\mathbf{2 . 1 8}$ \\
Jiyehtan & $-\mathbf{0 . 6 6}$ & $-\mathbf{0 . 9 4}$ & 2.33 \\
Alishan & -0.09 & $-\mathbf{0 . 3 4}$ & 2.13 \\
Hengchun & $-\mathbf{0 . 6 2}$ & $-\mathbf{0 . 6 1}$ & 0.04 \\
Keelung & $-\mathbf{0 . 6 2}$ & $\mathbf{0 . 3 8}$ & $-\mathbf{4 . 3 9}$ \\
Ilan & -0.15 & $\mathbf{0 . 4 4}$ & -2.20 \\
Hualien & -0.30 & $\mathbf{0 . 4 1}$ & -2.72 \\
Taitung & $-\mathbf{0 . 6 4}$ & 0.17 & $-\mathbf{3 . 4 0}$ \\
Tamshui & -0.36 & $-\mathbf{0 . 6 8}$ & 2.02 \\
Chengkung & $-\mathbf{0 . 5 5}$ & 0.13 & $-\mathbf{2 . 9 7}$ \\
Tawu & -0.16 & -0.36 & 1.29 \\
Pengchiayu & -0.15 & 0.20 & -1.09 \\
Penghu & 0.002 & -0.18 & 1.30 \\
Lanyu & -0.09 & 0.17 & -0.79 \\
Yushan & -0.23 & $\mathbf{0 . 9 3}$ & $-\mathbf{4 . 1 8}$ \\
Nighttime & & & \\
Taipei & -0.11 & $\mathbf{1 . 7 9}$ & $-\mathbf{8 . 7 1}$ \\
Taichung & -0.29 & $\mathbf{1 . 7 1}$ & $\mathbf{- 9 . 3 6}$ \\
Tainan & 0.02 & $\mathbf{1 . 3 6}$ & $-\mathbf{5 . 8 2}$ \\
Hsinchu & $-\mathbf{0 . 4 9}$ & $\mathbf{1 . 1 5}$ & $-\mathbf{8 . 1 6}$ \\
Jiyehtan & $-\mathbf{0 . 4 5}$ & $\mathbf{0 . 3 8}$ & $-\mathbf{3 . 3 4}$ \\
Alishan & 0.31 & $\mathbf{1 . 6 3}$ & $-\mathbf{6 . 7 3}$ \\
Hengchun & $\mathbf{- 0 . 6 3}$ & $\mathbf{0 . 5 2}$ & $\mathbf{- 5 . 2 9}$ \\
Keelung & $-\mathbf{0 . 4 7}$ & $\mathbf{0 . 9 8}$ & $-\mathbf{6 . 5 9}$ \\
Ilan & -0.32 & $\mathbf{0 . 8 8}$ & $-\mathbf{5 . 8 8}$ \\
Hualien & -0.22 & $\mathbf{1 . 1 1}$ & $-\mathbf{6 . 2 2}$ \\
Taitung & $-\mathbf{0 . 5 7}$ & $\mathbf{1 . 0 3}$ & $-\mathbf{7 . 6 0}$ \\
Tamshui & $-\mathbf{0 . 5 0}$ & 0.30 & $-\mathbf{3 . 3 0}$ \\
Chengkung & $-\mathbf{0 . 5 5}$ & $\mathbf{0 . 4 0}$ & $-\mathbf{4 . 5 7}$ \\
Tawu & -0.19 & 0.23 & -1.5 \\
Pengchiayu & -0.12 & $\mathbf{0 . 6 8}$ & -272 \\
Penghu & -0.10 & $\mathbf{0 . 4 9}$ & $-\mathbf{2 . 5 0}$ \\
Lanyu & -0.02 & $\mathbf{0 . 5 1}$ & $-\mathbf{2 . 2 6}$ \\
Yushan & -0.10 & $\mathbf{1 . 1 0}$ & $-\mathbf{6 . 3 3}$ \\
\hline & & & \\
\hline
\end{tabular}

some anthropogenic activities. It is also possible that a reduction in evaporation or evapotranspiration flux resulting from land use change during the past few decades lead to a decrease in moisture supply to the surface air.

\section{c. Influence of urban heat island effects}

To address the impacts of urban heat islands effects on the observed meteorological parameters, the 18 stations are grouped into five subgroups according to their degrees of urbanization and locations (Table 3). Group 1 (G1) are consisted of main urban centers such as Taipei, Taichung, and Tainan. Group 2 (G2) are suburban stations like Tamshui, Keelung, Hsinchu, Hualien, and Taitung. Group 3 (G3) are rural stations such as Chengkung, Tawu, and Hengchun. Group 4 (G4) are stations located in mountain area, that is, Jiyehtan and Alishan. Group 5 (G5) are off-coast stations, namely, Pengchiayu, Penghu, and Lanyu. We also applied Prais-Winsten estimates to derive the trends of the different weather parameters of the five groups. The temperature trend is largest in the urban group, consistent with what we have seen in Fig. 4. The warming trends are also significant in other areas, except for the rural group. For dewpoint, the trends are all negative except for G5, but the changes are relatively small and are significant only for G2 and G3, consistent with Fig. 7. It is reassuring to note that $\left(T-T_{d}\right)$ and $\mathrm{RH}$ show progressively greater trends with an increasing degree of urbanization. Assuming offshore islands can represent the regional background, one can subtract the trend of G5 from those in other regions to deduce the local effect. By doing so, one can easily see that the local/urban effect on $T$ in the G1 region is much greater than that in the other regions. Similarly, the local/urban effect on $T-T_{d}$ in regions G1 and G2 are larger than those over G3 and G4 by a factor of 2 . The contrast is even greater in the trends of RH. The trends of $T_{\mathrm{Min}}$ and DTR also show the strongest signal of heat island effect in urban centers.

\section{d. Frequency distribution of relative humidity}

Frequency distributions of RH for whole days and averaged for the daytime and nighttime over 18 stations for 1961-2005 (averaged over each decade except 200105, which has only $5 \mathrm{yr}$ of data) are shown in Fig. 8. The daytime RH frequency distributions show little change, but those of the nighttime are a different story: the occurrence of $\mathrm{RH}>85 \%$ in nighttime has decreased by about a factor of 2 in four and a half decades. Because high $\mathrm{RH}$ in near-surface air is often related to fog formation, one would expect a significant decrease in the occurrence of fog. Indeed, fog events have become substantially less frequent throughout Taiwan. They have practically disappeared in the three large urban centers, and they have even decreased at high-elevation stations, for example, Jiyehtan (by $40 \%$ ) and Alishan (by $50 \%$ ).

\section{e. Diurnal temperature range}

Table 2 shows changes over four decades for the yearly average daytime maximum $\left(T_{\mathrm{Max}}\right)$, nighttime minimum $\left(T_{\mathrm{Min}}\right)$, and DTR. The autoregression procedure mentioned in section 3a is also applied to estimate the trends of $T_{\text {Max }}, T_{\text {Min }}$, and DTR. Given the relatively large temperature increase over Taiwan (Fig. 3), it is a surprise to see that $T_{\mathrm{Max}}$ is mostly negative. In fact, only coastal stations and off-coast stations have consistent positive $T_{\text {Max }}$. Two of the three major urban centers even show small decreases in $T_{\mathrm{Max}}$. In contrast, nearly all stations 

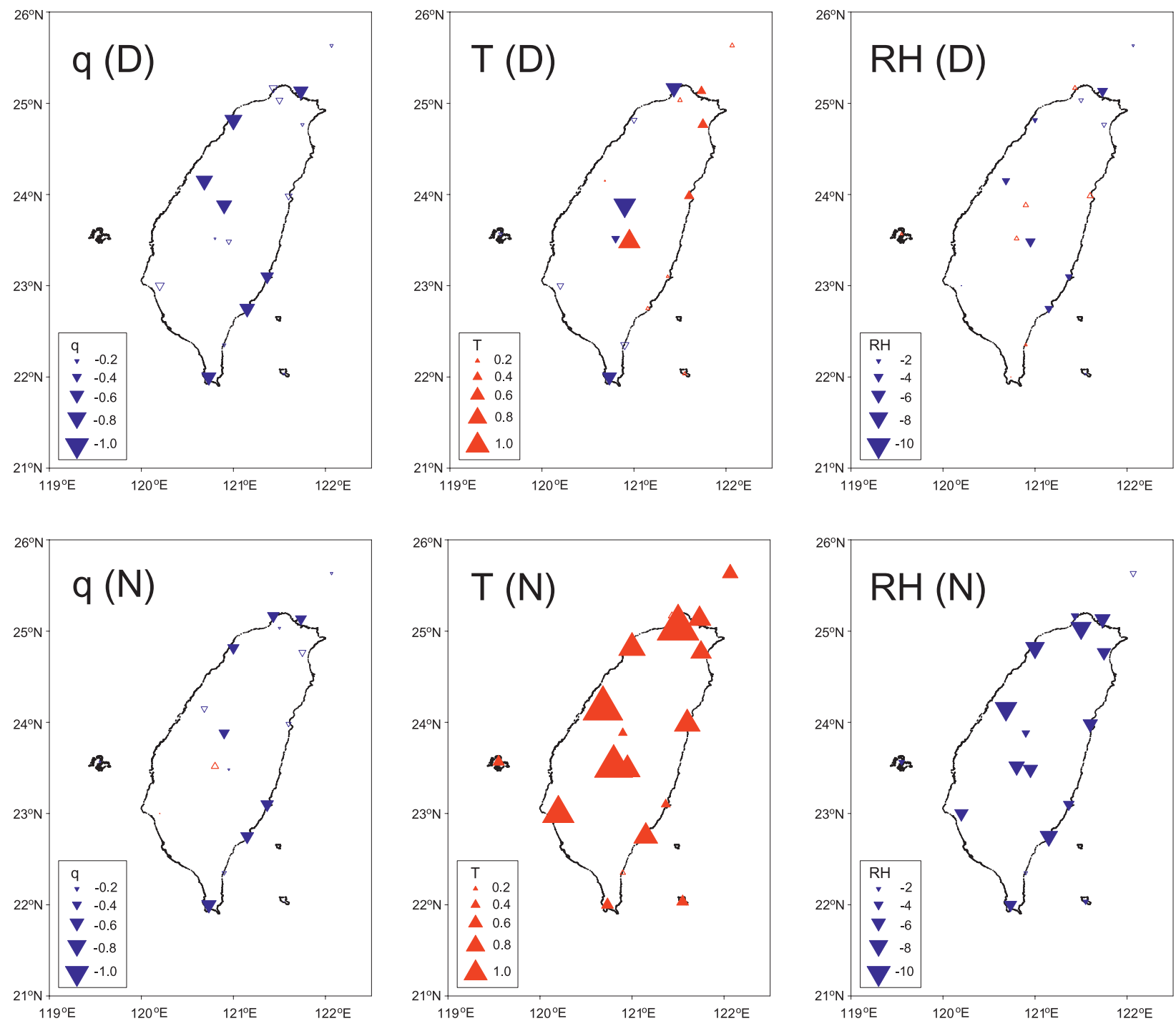

FIG. 7. Linear trends of specific humidity $(q)$, temperature $(T)$, and relative humidity $(\mathrm{RH})$ for the daytime (D) and nighttime (N). Positive (upward-pointing triangles, red) and negative (downward-pointing triangles, blue) trends are denoted. Magnitudes of trends are proportional to the size of triangles for $q$ [g kg ${ }^{-1}$ ( 4 decades $\left.)^{-1}\right]$, for $T\left[{ }^{\circ} \mathrm{C}(4 \text { decades })^{-1}\right]$, and for $\mathrm{RH}\left[\%(4 \mathrm{decades})^{-1}\right]$. Filled triangles indicate statistical significance at the $95 \%$ confidence level.

have positive $T_{\mathrm{Min}}$, and most of them are statistically significant. As a result, the decreasing trends in DTR are significant at most stations. Similar to the nighttime temperature, the trends are greater in major urban centers and decrease gradually going into remote areas. Nevertheless, the trends remain significant in two of the three offshore islands in all seasons except in summer, suggesting again that, in addition to local process, regionalscale or greater processes also contribute to the trends in the DTR.

A top candidate for the local process is the urban heat island effect, which is well recognized to be the greatest at night and smallest during the day because of the absorp- tion of solar heating by buildings and roads in daytime and release of heat at night, whereas evapotranspiration by vegetation greatly reduces the solar heating of the surface, resulting in a smaller release of heat at night (Oke 1982; Stull 1988). Changing forested lands to agricultural uses may also contribute to the temperature trends. Other candidates are the direct and indirect effects of anthropogenic aerosols, which cool the surface air in the day and warm it at night (Hansen et al. 1995, 1997, 2005; Liu et al. 2002; Huang et al. 2006). The aerosol effects (direct and indirect) can be local as well as regional in scale depending on how far the aerosols or the clouds (affected by aerosols) are transported. An important 
TABLE 2. Same as Table 1, except for the daily maximum temperature $\left(T_{\mathrm{Max}}\right)$, daily minimum temperature $\left(T_{\mathrm{Min}}\right)$, and DTR. The units are ${ }^{\circ} \mathrm{C}(4 \text { decades })^{-1}$.

\begin{tabular}{lrrr}
\hline \hline Station & $T_{\text {Max }}$ & $T_{\text {Min }}$ & DTR \\
\hline Taipei & -0.03 & $\mathbf{1 . 9 2}$ & $-\mathbf{1 . 8 2}$ \\
Taichung & -0.17 & $\mathbf{1 . 7 5}$ & $-\mathbf{1 . 8 3}$ \\
Tainan & 0.03 & $\mathbf{1 . 4 7}$ & $-\mathbf{1 . 3 7}$ \\
Hsinchu & -0.07 & $\mathbf{1 . 2 0}$ & $-\mathbf{1 . 2 5}$ \\
Jiyehtan & -0.23 & $\mathbf{0 . 5 5}$ & $\mathbf{- 0 . 8 0}$ \\
Alishan & 0.29 & $\mathbf{2 . 2 1}$ & $-\mathbf{2 . 0 2}$ \\
Hengchun & -0.10 & $\mathbf{0 . 5 6}$ & $-\mathbf{0 . 6 2}$ \\
Keelung & $\mathbf{0 . 9 4}$ & $\mathbf{0 . 8 6}$ & 0.13 \\
Ilan & $\mathbf{0 . 9 0}$ & $\mathbf{1 . 0 3}$ & -0.13 \\
Hualien & 0.52 & $\mathbf{1 . 2 5}$ & $-\mathbf{0 . 8 0}$ \\
Taitung & 0.43 & $\mathbf{1 . 1 7}$ & $-\mathbf{0 . 6 8}$ \\
Tamshui & 0.18 & 0.33 & -0.21 \\
Chengkung & $\mathbf{1 . 1 0}$ & 0.12 & $\mathbf{0 . 9 8}$ \\
Tawu & 0.03 & 0.27 & -0.23 \\
Pengchiayu & $\mathbf{0 . 8 3}$ & $\mathbf{0 . 4 6}$ & $\mathbf{0 . 3 6}$ \\
Penghu & 0.38 & $\mathbf{0 . 5 4}$ & -0.07 \\
Lanyu & $\mathbf{0 . 6 2}$ & $\mathbf{0 . 6 2}$ & 0.04 \\
Yushan & $\mathbf{1 . 3 4}$ & $\mathbf{1 . 1 4}$ & 0.27 \\
\hline
\end{tabular}

question is as follows: which process is the primary cause? In the daytime, the aerosol cooling effects must be the controlling process because they tend to counterbalance the global greenhouse warming and the small daytime heating of the urban heat island effect. In the nighttime, all three processes act to increase $T_{\mathrm{Min}}$. Their relative effects cannot be accurately determined, but judging from Table 3, they are probably on the same order of magnitude.

As discussed in the introduction, decreasing DTR has been observed in all major land areas of the world. Recently, Qian and Lin (2004) reported decreasing trends of DTR over large areas in China during 19612000. The decreases in China are mostly smaller than those over Taiwan, which are probably the result of a higher degree of urbanization of the latter.

\section{f. Temperature extremes}

Another important diurnally asymmetric change is the extremes in temperature. Figure 9 shows trends of the occurrence of daily minimum temperature that is lower than $13^{\circ} \mathrm{C}$, as well as daily maximum temperature higher than $36^{\circ} \mathrm{C}$. The reduction in the occurrence of low extreme temperatures definitely has a regional component, because the decreasing trends also can be found at the offshore stations. It is most likely associated with the regional/global warming and/or the weakening of the northeasterly monsoon (Hsu and Chen 2002). This is consistent with studies in mainland China, showing that the frequency of low extreme temperature has decreased significantly (Yan et al. 2002; Qian and Lin 2004;
TABLE 3 . Trends (1961-2005) of $T, T_{d}, T-T_{d}$, RH, $T_{\text {Max }}, T_{\text {Min }}$, and DTR for five groups of stations as described in the text. Trends in bold represent statistical significance above the $95 \%$ confidence level. Unit for temperatures is ${ }^{\circ} \mathrm{C}(4 \text { decades })^{-1}$ and the unit for RH is \% decade ${ }^{-1}$.

\begin{tabular}{lrrrrr}
\hline \hline Parameter & $\begin{array}{c}\text { Urban } \\
(\mathrm{G} 1)\end{array}$ & $\begin{array}{c}\text { Suburban } \\
(\mathrm{G} 2)\end{array}$ & $\begin{array}{r}\text { Rural } \\
(\mathrm{G} 3)\end{array}$ & $\begin{array}{c}\text { Mountains } \\
(\mathrm{G} 4)\end{array}$ & $\begin{array}{c}\text { Islands } \\
(\mathrm{G} 5)\end{array}$ \\
\hline$T$ & $\mathbf{0 . 2 4}$ & $\mathbf{0 . 1 6}$ & 0.06 & $\mathbf{0 . 1 4}$ & $\mathbf{0 . 1 1}$ \\
$T_{d}$ & -0.06 & $-\mathbf{0 . 1 1}$ & $-\mathbf{0 . 1 0}$ & -0.01 & 0.02 \\
$T-T_{d}$ & $\mathbf{0 . 2 9}$ & $\mathbf{0 . 2 6}$ & $\mathbf{0 . 1 6}$ & $\mathbf{0 . 1 4}$ & $\mathbf{0 . 1 0}$ \\
RH & $-\mathbf{1 . 3 9}$ & $-\mathbf{1 . 2 3}$ & $-\mathbf{0 . 7 2}$ & $-\mathbf{0 . 6 1}$ & -0.44 \\
$T_{\text {Max }}$ & -0.02 & $\mathbf{0 . 1 3}$ & $\mathbf{0 . 0 9}$ & 0.01 & $\mathbf{0 . 1 6}$ \\
$T_{\text {Min }}$ & $\mathbf{0 . 4 3}$ & $\mathbf{0 . 2 5}$ & $\mathbf{0 . 0 8}$ & $\mathbf{0 . 3 4}$ & $\mathbf{0 . 1 4}$ \\
DTR & $-\mathbf{0 . 4 1}$ & $-\mathbf{0 . 1 2}$ & 0.01 & $-\mathbf{0 . 3 4}$ & 0.02 \\
\hline
\end{tabular}

Qian and Qin 2006). However, the magnitude of trends over urban stations $\left(-8.7\right.$ days decade $\left.{ }^{-1}\right)$ is significantly larger than those over the suburban $\left(-4.4\right.$ days decade $\left.^{-1}\right)$ and offshore $\left(-2.9\right.$ days decade $\left.{ }^{-1}\right)$ stations. Again, this provides evidence for the impact of local changes (e.g., urban heat island effect) on low extreme temperatures in winter. Note that there is no significant change in low extreme temperatures in the rural stations because these three stations are located in southern Taiwan where temperatures seldom get below $13^{\circ} \mathrm{C}$. They do show a similar decrease as other rural stations if the criterion is set at a higher temperature, such as $15^{\circ} \mathrm{C}$. The largest magnitude of trends on low extreme temperature over urban areas can be attributed to urban heat island effect. There are no obvious trends in the high extreme temperatures except in urban centers. The reason for such a phenomenon to occur is obviously the same as the lack of trend for daytime temperature maximum $T_{\mathrm{Max}}$, discussed in the last section. That is, in the daytime, the aerosol cooling effects are the controlling processes because they tend to counterbalance the global greenhouse warming and the small daytime heating of the urban heat island effect. There is a significant positive trend in the high extreme temperature in Taipei only.

In regards to the changes of extreme high temperature, the results in Taiwan are different from those in mainland China where there is an increasing frequency of extreme high temperature in broad areas, except in the northern part of northeast China and the northern part of the Xinjiang region (Yan et al. 2002; Qian and Lin 2004; Qian and Qin 2006). We do not have an explanation for this difference.

\section{Changes in character of precipitation}

With large reductions in the occurrence of high relative humidity and the frequency of fog, one would expect the reductions to extend to light precipitation. Liu 


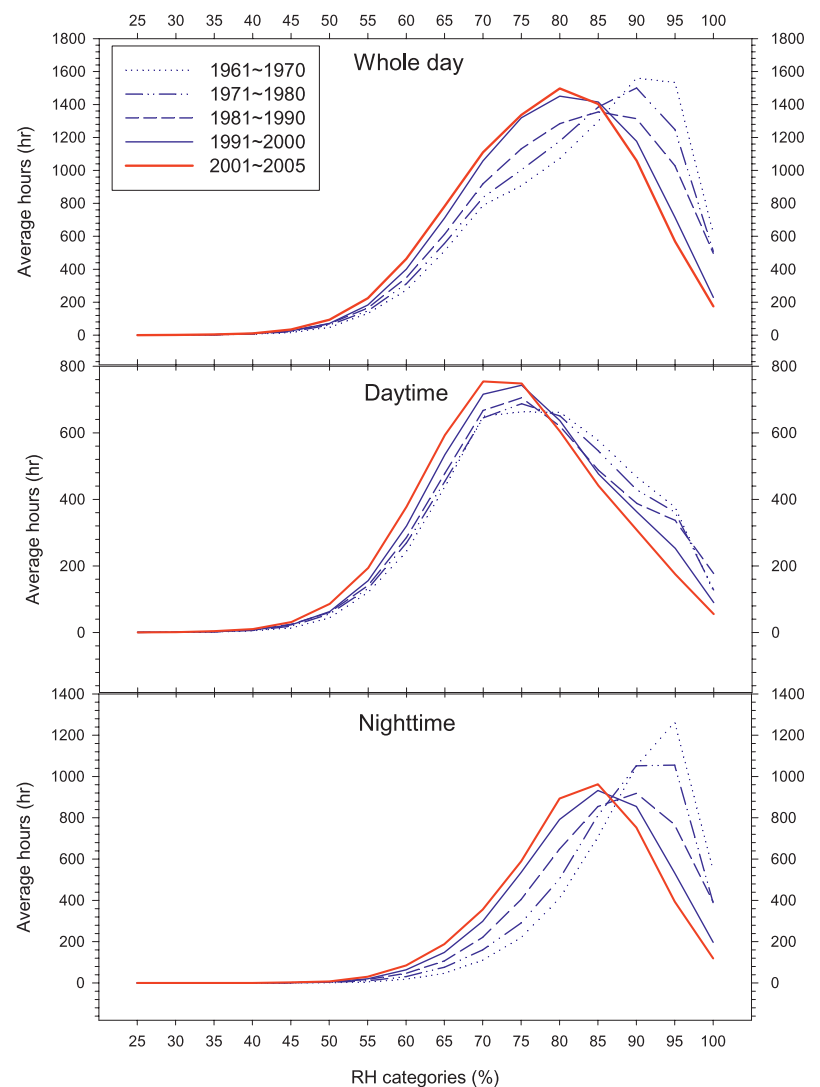

FIG. 8. Frequency distribution of relative humidity averaged over 18 meteorological stations for whole day, and daytime and nighttime periods for five time periods, as indicated.

et al. (2002) and Hsu and Chen (2002) noticed that precipitation hours (or days) had decreased by about $25 \%$ since about 1980 , while the total amount of precipitation had little trend, resulting in a $25 \%$ increase in precipitation intensity. Liu et al. (2002) also noticed that the increase in precipitation intensity was due to a reduction in light precipitation $\left(<4 \mathrm{~mm} \mathrm{~h}^{-1}\right)$ and an increase in heavy precipitation. The decreasing trend of light precipitation behaves qualitatively differently from the trends of temperature, relative humidity, and sunshine duration in the following two key aspects: one is that the decreasing trend of light precipitation is more significant in rural and remote areas than urban areas, and the other is that the decreasing trend of light precipitation does not exhibit any diurnal asymmetry. These differences clearly suggest that the cause of the reduction in light precipitation is a regional-scale rather than a local-scale process. An increase in heavy precipitation $\left(>10 \mathrm{~mm} \mathrm{~h}^{-1}\right)$ was found that nearly compensated for the decrease in the light precipitation (Fig. 10). Similar trends in precipitation have been observed in many regions in Asia, including China, Japan,

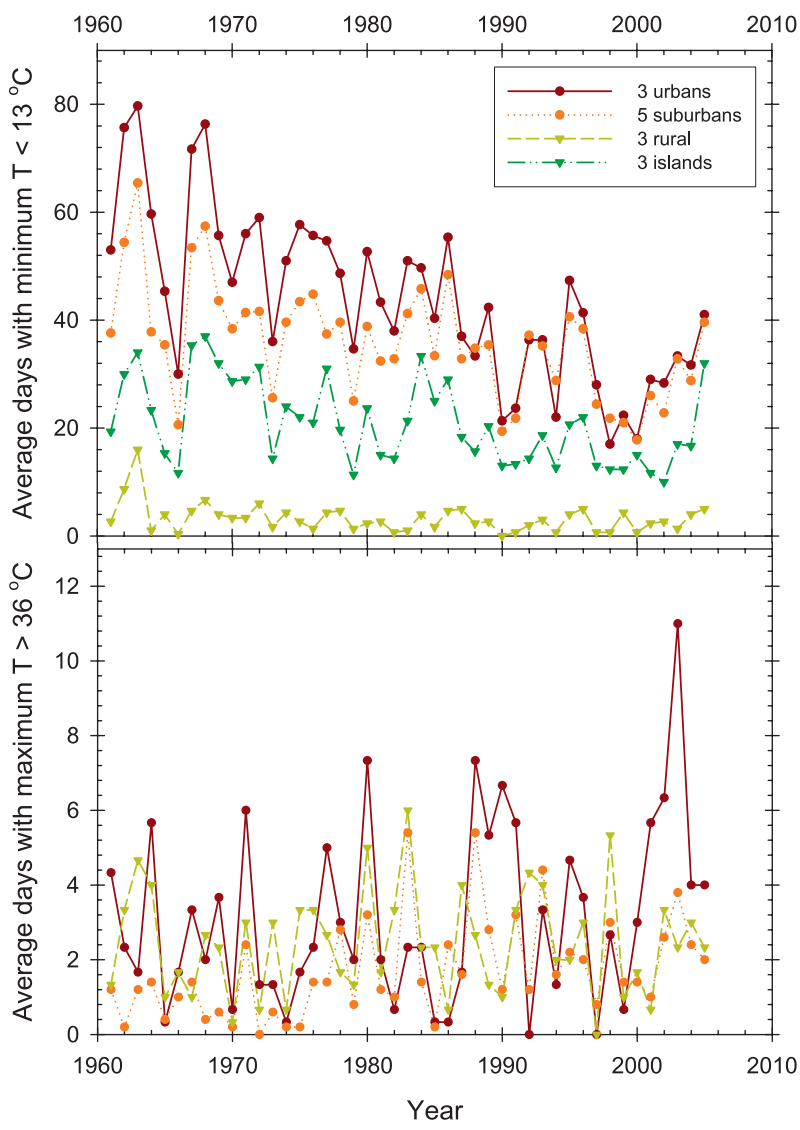

FIG. 9. The yearly occurrence of (top) extreme low and (bottom) extreme high temperature averaged for four different groups of stations from 1961 to 2005 .

and India (Liu et al. 2005; Fujibe et al. 2005; Goswami et al. 2006; Qian et al. 2007). In contrast, only the increase in the heavy precipitation has been consistently observed over the United States (Karl and Knight 1998; Groisman et al. 2004), Europe (Klein Tank and Können 2003), and other land areas (Manton et al. 2001; Groisman et al. 2005). In addition, in a key investigation that included precipitation over oceans, Lau and $\mathrm{Wu}$ (2007) analyzed trends of precipitation in the tropics $\left(30^{\circ} \mathrm{S}-30^{\circ} \mathrm{N}\right)$ during $1979-2003$ by using combined satellite- and ground-based global rainfall datasets. Two robust trends that they found were positive trends in light precipitation (bottom 5\%) and heavy precipitation (top $10 \%$ ) over the oceans. Interestingly, they also found a negative trend for moderate rain events $(25 \%-75 \%)$.

Nearly all of the studies cited above attributed the widespread increases of heavy precipitation to global warming. As mentioned in section $3 b$, tropospheric warming leads to increases in the water-holding capacity of the atmosphere and, in turn, the heavy precipitation 


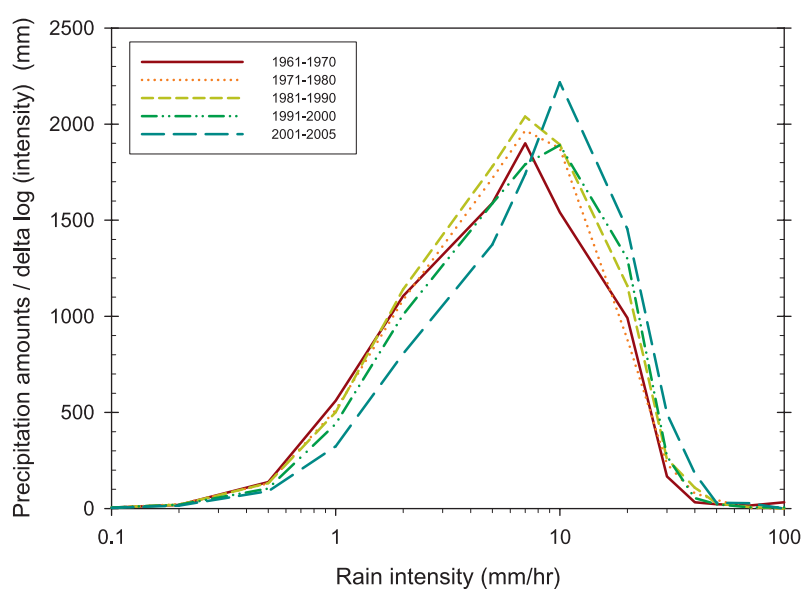

FIG. 10. Frequency (in amount of precipitation) distribution of precipitation intensity averaged over 15 meteorological stations for five time periods, as indicated.

should increase at the same rate as atmospheric moisture because precipitation rates from storms are determined by low-level moisture convergence (Trenberth et al. 2003). Furthermore, Trenberth et al. (2003) theorized that the increase of heavy rainfalls can even exceed the moisture increase because the additional latent heat released feeds back and invigorates the storms. Their theory was corroborated by the work of Sun et al. (2007), who analyzed monthly and daily precipitation data from an ensemble of 17 latest generations of coupled global climate models for changes in precipitation intensity and frequency under three future greenhouse emission scenarios. Their results show that, under global warming environment, the rate of increase of precipitation increases with the intensity of precipitation and the increase of very heavy precipitation can substantially exceed the moisture increase.

Changes to the Asian monsoon can be eliminated as a major cause because seasonal dependence of the decrease in light precipitation or the increase of heavy precipitation is negligible in the data of Taiwan. This is also the case in Japan (Fujibe et al. 2005).

There is no consensus on the cause of the decrease in light precipitation. Warner and Twomey (1967) hypothesized that the large number of anthropogenic cloud condensation nuclei $(\mathrm{CCN})$ could lead to smaller cloud droplets than those under natural conditions, and slow down collision and coalescence growth of cloud droplets (i.e., indirect effect of aerosols). Thus, the precipitation would be delayed and even suppressed. The hypothesis can explain the reduction in precipitation hours as noted by Liu et al. (2002). Another mechanism by which aerosols may reduce light precipitation is through black carbon, which, once incorporated into clouds, can lead to heating and evaporation of cloud droplets. Gong et al. (2007) also argued that the decrease in light precipitation in China was a result of indirect aerosol effects. On the other hand, Liu et al. (2005), Fujibe et al. (2005), Goswami et al. (2006), and Qian et al. (2007) argued that the reduction of light precipitation was a result of global or regional warming, similar to the increase of heavy precipitation. However, the global warming explanation is not consistent with the fact that many regions such as the United States and Europe do not show any significant decrease in light precipitation. Furthermore, results from the ensemble of climate models analyzed by Sun et al. (2007) showed a negligible decrease of light precipitation for the 2-K warming scenario. More importantly, Lau and $\mathrm{Wu}$ (2007) showed that the light precipitation over the tropical oceans had a significant positive (rather than negative) trend during 1979-2003 in which period global temperature had risen by as much as $0.5 \mathrm{~K}$ (Solomon et al. 2007). In this regard, the aerosol explanation is more favorable because oceans are relatively clean compared to Asia and the Pacific Rim, which are the only areas in the world where emissions of anthropogenic aerosols have increased consistently over the last half-century (Streets et al. 2003; Akimoto 2003).

Increases in heavy precipitation will lead to increased and worse floods. In Taiwan, where typhoons and torrential rains are common, any significant increases in the intensity and frequency of heavy precipitation are of grave concern. Figure 10 shows that very heavy precipitation around $20 \mathrm{~mm} \mathrm{~h}^{-1}$ has increased by about $100 \%$ and is statistically significant. A similar analysis of precipitation data for typhoons that have made landfall in Taiwan also shows a comparable increase in heavy precipitation.

We notice that the high time resolution hourly data shown in Fig. 10 depict the potential disastrous problem more clearly and precisely than the commonly used daily datasets. This result lends strong support for the recommendation by Trenberth et al. (2003) that hourly resolution analyses are needed for both observation and modeling data of precipitation, for the understanding of the changing character of precipitation in a global warming environment.

A persistent, chronic decrease of light precipitation poses a serious threat to the drought problem because light precipitation is a critical source of water in the replenishment and retention of soil moisture. This is a particularly serious problem for southwestern Taiwan where drought is frequent because of very little precipitation in the winter half of the year. In fact, we suspect that the chronic decrease of light precipitation may even be a significant contributor to the desertification in some parts of Asia. 


\section{Conclusions and implications}

In this study, 45 years of hourly meteorological data, including humidity, temperature, and precipitation, have been analyzed to examine the regional climate change over Taiwan. We find that the average increasing trend of temperature at large urban stations are 2.5 times greater than that of medium-sized urban stations and offshore stations, suggesting that a local effect(s) is the major cause of the trend. In addition, diurnally asymmetric trends of temperature and humidity have occurred at the stations except one off-coast island and one elevated station. Nearly all of the temperature increase in Taiwan can be attributed to the increase in nighttime, while daytime increase is negligible. The decrease in DTR is also largest in major urban areas, becoming smaller in smaller cities, but remaining significant even in offshore islands. These trends are very similar to a decreasing trend in sunshine duration found by Liu et al. (2002). Furthermore, seasonal and the diurnal characteristics of temperature, relative humidity, and specific humidity indicate that the diurnally asymmetric warming trends in Taiwan are most likely caused by a local process(es) superposed over a regional background process(es). The local processes may include land use changes and direct and indirect effects of aerosols. The aerosol effects can be local and/or regional, depending how far the aerosols are transported.

The large increase in nighttime temperature can lead to a substantial decrease in the occurrence of high relative humidity. Relative humidity above $90 \%$ became less frequent by about a factor of 2 from 1961 to 2005 . Furthermore, the decrease was greater in the urban areas but remained significant throughout Taiwan. A drastic decrease in the frequency of fog has occurred, most likely resulting from the large drop in high relative humidity during the nighttime. In fact, fogs have essentially disappeared in major cities, and substantial decreases extend to rural areas. The large decrease in fog frequency together with the reduction in relative humidity may have a far-reaching impact on the ecosystem because these changes can reduce the availability of water to plants, such as through the formation of dew.

We find a significant decreasing trend in light precipitation less than $4 \mathrm{~mm} \mathrm{~h}^{-1}$ and an increase in heavy precipitation $\left(>10 \mathrm{~mm} \mathrm{~h}^{-1}\right)$ that nearly compensates the decrease in the light precipitation. Similar trends in precipitation have been observed in many regions in Asia, including China, Japan, and India (Liu et al. 2005; Fujibe et al. 2005; Goswami et al. 2006; Qian et al. 2007). In contrast, only the increase in the heavy precipitation has been consistently observed over the United States
(Karl and Knight 1998; Groisman et al. 2004), Europe (Klein Tank and Können 2003), and other land areas (Manton et al. 2001; Groisman et al. 2005). In addition, in a key investigation that included precipitation over oceans, Lau and Wu (2007) analyzed trends of precipitation in the tropics $\left(30^{\circ} \mathrm{S}-30^{\circ} \mathrm{N}\right)$ during $1979-2003$ by using combined satellite- and ground-based global rainfall datasets. They found significant positive trends in both light precipitation (bottom 5\%) and heavy precipitation (top $10 \%$ ) over the oceans.

The worldwide increases of heavy precipitation are most likely caused by global warming. However, there is no consensus on the cause of the decreases in light precipitation, which has occurred primarily over land areas of Asia and the Pacific Rim. Indirect effects of anthropogenic aerosols seem to be the most reasonable cause because Asia and the Pacific Rim are the only areas in the world where emissions of anthropogenic aerosols have increased consistently over the last halfcentury.

Increases in heavy precipitation will lead to increased and worse floods. Heavy precipitation around $20 \mathrm{~mm} \mathrm{~h}^{-1}$ in Taiwan has increased by as much as $100 \%$. In Taiwan, where typhoons and torrential rains are common, any significant increases in the intensity and frequency of heavy precipitation are of grave concern.

The persistent and chronic decrease of light precipitation poses a serious threat to the drought problem, because light precipitation is a critical source of water in the replenishment and retention of soil moisture. This is a particularly serious problem for southwestern Taiwan where drought is frequent because of very little precipitation in the winter half of the year. In fact, we suspect that the chronic decrease of light precipitation may even be a significant contributor to the desertification in some parts of Asia.

We notice that the high time resolution hourly data used in this study underscore the potentially disastrous problem more clearly and precisely than the commonly used daily datasets. This result lends strong support for the recommendation by Trenberth et al. (2003) that hourly resolution analyses are needed for both observation and modeling data of precipitation, for the understanding of the changing character of precipitation in a global warming environment.

The cause-effect relationships of the trends/changes of temperature, humidity, and precipitation discussed in this work are extremely complex. Local, regional, and global processes all play significant roles in these trends/ changes. Our understanding of these processes so far is rudimentary at best. More comprehensive data analyses and modeling investigations are needed for a fundamental understanding. 
Acknowledgments. The work is supported in part by the theme research proposal to Academia Sinica entitled "Particulate matter and its environmental impacts in Taiwan," the theme research proposal to Academia Sinica entitled "Heat island effect over Taiwan's western plain and its impacts on climate changes," NSC 96-2111-M-001005-MY3, and NSC 96-2752-M-001-006-PAE. We thank the Data Bank for Atmospheric Research, Department of Atmospheric Sciences, National Taiwan University for the data in Taiwan. We also would like to acknowledge the U.K. Met Office for providing HadISST 1.1, MOHMATN4, and CRUTEM3 data.

\section{REFERENCES}

Akimoto, H., 2003: Global air quality and pollution. Science, 302, 1716-1719.

Allen, M. R., and W. J. Ingram, 2002: Constraints on future changes in climate and the hydrological cycle. Nature, 419, 224-232.

Arnfield, A. J., 2003: Two decades of urban climate research: A review of turbulence, exchanges of energy and water, and the urban heat island. Int. J. Climatol., 23, 1-26.

Bloomfield, P., 1992: Trends in global temperature. Climatic Change, 21, 1-16.

Brohan, P., J. J. Kennedy, I. Haris, S. F. B. Tett, and P. D. Jones, 2006: Uncertainty estimates in regional and global observed temperature changes: A new dataset from 1850. J. Geophys. Res., 111, D12106, doi:10.1029/2005JD006548.

Campbell, G. G., and T. H. Vonder Haar, 1997: Comparison of surface temperature minimum and maximum and satellite measured cloudiness and radiation budget. J. Geophys. Res., 102, 16 639-16 645.

Choudhury, A. H., R. Hubata, and R. D. St. Louis, 1999: Understanding time-series regression estimators. Amer. Stat., 53, 342-348.

Collatz, G. J., L. Bounoua, S. O. Los, D. A. Randall, I. Y. Fung, and P. J. Sellers, 2000: A mechanism for the influence of vegetation on the response of diurnal temperature range to changing climate. Geophys. Res. Lett., 27, 3381-3384.

Corbett, J. J., J. J. Winebrake, E. Green, P. Kasibhatla, V. Eyring, and A. Lauer, 2007: Mortality from ship emissions: A global assessment. Environ. Sci. Technol., 41, 8512-8518.

Dai, A., 2006: Recent climatology, variability and trends in global surface humidity. J. Climate, 19, 3589-3606.

$\longrightarrow$, K. E. Trenberth, and T. R. Karl, 1999: Effects of clouds, soil moisture, precipitation, and water vapor on diurnal temperature range. J. Climate, 12, 2451-2473.

Durre, I., and J. M. Wallace, 2001a: Factors influencing the coldseason diurnal temperature range in the United States. J. Climate, 14, 3263-3278.

$\longrightarrow$, and _ 2001b: The warm season dip in diurnal temperature range over the eastern United States. J. Climate, 14, 354-360.

Eastering, D. R., and Coauthors, 1997: Maximum and minimum temperature trends for the globe. Science, 277, 364-367.

Eyring, V., H. W. Köhler, J. van Aardenne, and A. Lauer, 2005: Emissions from international shipping: 1. The last 50 years. J. Geophys. Res., 110, D17305, doi:10.1029/2004JD005619.

Fujibe, F., N. Yamazaki, M. Katsuyama, and K. Kobayashi, 2005: The increasing trends of intense precipitation in Japan based on four-hourly data for a hundred years. SOLA, 1, 41-44.
Gong, D.-Y., C.-H. Ho, D. Chen, Y. Qian, Y.-S. Choi, and J. Kim, 2007: Weekly cycle of aerosol-meteorology interaction over China. J. Geophys. Res., 112, D22202, doi:10.1029/2007JD008888.

Goswami, B. N., V. Venugopal, D. Sengupta, M. S. Madhusoodanan, and P. K. Xavier, 2006: Increasing trend of extreme rain events over India in a warming environment. Science, 314, 1442-1445.

Groisman, P. Y., R. W. Knight, T. R. Karl, D. R. Easterling, B. M. Sun, and J. H. Lawrimore, 2004: Contemporary changes of the hydrological cycle over the contiguous United States: Trends derived from in situ observations. J. Hydrometeor., 5, 64-85.

— — , D. R. Easterling, T. R. Karl, G. C. Hegerl, and V. A. N. Razuvaev, 2005: Trends in intense precipitation in the climate record. J. Climate, 18, 1326-1350.

Hansen, J., M. Sato, and R. Ruedy, 1995: Long-term changes of the diurnal temperature cycle: Implications about mechanisms of global climate change. Atmos. Res., 37, 175-209.

,-- , and — 1997: Radiative forcing and climate response. J. Geophys. Res., 102, 6831-6864.

— , and Coauthors, 2005: Efficacy of climate forcings. J. Geophys. Res., 110, D18104, doi:10.1029/2005JD005776.

Hsu, H.-H., and C.-T. Chen, 2002: Observed and projected climate change in Taiwan. Meteor. Atmos. Phys., 79, 87-104.

Huang, Y., R. E. Dickinson, and W. L. Chameides, 2006: Impact of aerosol indirect effect on surface temperature over East Asia Proc. Natl. Acad. Sci. USA, 103, 4371-4376.

Jones, P. D., 1989: The influence of ENSO on global temperature. Climate Monitor, 17, 80-89.

—, M. New, D. E. Parker, S. Martin, and I. G. Rigor, 1999: Surface air temperature and its variations over the last 150 years. Rev. Geophys., 37, 173-199.

Karl, T. R., and R. W. Knight, 1998: Secular trends of precipitation amount, frequency, and intensity in the United States. Bull. Amer. Meteor. Soc., 79, 231-241.

_ - and Coauthors, 1993: A new perspective on recent global warming: Asymmetric symmetric trends of daily maximum and minimum temperature. Bull. Amer. Meteor. Soc., 74, 1007-1023.

Klein Tank, A. M. G., and G. P. Können, 2003: Trends in indices of daily temperature and precipitation extremes in Europe, 1946-99. J. Climate, 16, 3665-3680.

Lau, K.-M., and H.-T. Wu, 2007: Detecting trends in tropical rainfall characteristics, 1979-2003. Int. J. Climatol., 27, 979-988.

Lin, C.-Y., S. C. Liu, C. C. K. Chou, T. H. Liu, C.-T. Lee, C.-S. Yuan, C.-J. Shiu, and C.-Y. Young, 2004: Long-range transport of Asian dust and air pollutants to Taiwan. Terr. Atmos. Oceanic Sci., 15, 759-784.

Liu, B., M. Xu, M. Henderson, and Y. Qi, 2005: Observed trends of precipitation amount, frequency, and intensity in China, 1960-2000. J. Geophys. Res., 110, D08103, doi:10.1029/ 2004JD004864.

Liu, S. C., C.-H. Wang, C.-J. Shiu, H.-W. Chang, C.-K. Hsiao, and S.-H. Liaw, 2002: Reduction in sunshine duration over Taiwan: Causes and implications. Terr. Atmos. Oceanic Sci., 13, 523-545.

Manton, M. J., and Coauthors, 2001: Trends in extreme daily rainfall and temperature in Southeast Asia and the South Pacific: 1961-1998. Int. J. Climatol., 21, 269-284.

Oke, T. R., 1982: The energetic basis of the urban heat island. Quart. J. Roy. Meteor. Soc., 108, 1-24.

Parker, D. E., C. K. Folland, and M. Jackson, 1995: Marine surface temperature: Observed variations and data requirements. Climatic Change, 31, 559-600. 
Prais, S. J., and C. B. Winsten, 1954: Trend estimators and serial correlation. Cowles Commission Discussion Paper 383, 27 pp.

Qian, W., and X. Lin, 2004: Regional trends in recent temperature indices in China. Climate Res., 27, 119-134.

- , and A. Qin, 2006: Spatial-temporal characteristics of temperature variation in China. Meteor. Atmos. Phys., 93,1-16.

_ J. Fu, and Z. Yan, 2007: Decrease of light rain events in summer associated with a warming environment in China during 1961-2005. Geophys. Res. Lett., 34, L11705, doi:10.1029/ 2007GL029631.

Rayner, N. A., D. E. Parker, E. B. Horton, C. K. Folland, L. V. Alexander, D. P. Rowell, E. C. Kent, and A. Kaplan, 2003: Global analyses of sea surface temperature, sea ice, and night marine air temperature since the late nineteenth century. J. Geophys. Res., 108, 4407, doi:10.1029/2002JD002670.

- P. Brohan, D. E. Parker, C. K. Folland, J. J. Kennedy, M. Vanicek, T. Ansell, and S. F. B. Tett, 2006: Improved analyses of changes and uncertainties in marine temperature measured in situ since the mid-nineteenth century: The HadSST2 dataset. J. Climate, 19, 446-469.

Soden, B. J., R. T. Wetherald, G. L. Stenchikov, and A. Robock, 2002: Global cooling after the eruption of Mount Pinatubo: A test of climate feedback by water vapor. Science, 296, 727-730.

Solomon, S., D. Qin, M. Manning, Z. Chen, M. Marquis, K. B. Averyt, M. Tignor, and H. L. Miller, 2007: Climate Change 2007: The Physical Science Basis. Cambridge University Press, $996 \mathrm{pp}$.
Stenchikov, G. L., and A. Robock, 1995: Diurnally asymmetry of climatic response to increased $\mathrm{CO}_{2}$ and aerosols: Forcings and feedbacks. J. Geophys. Res., 100, 26 211-26 227.

Stone, D. A., and A. J. Weaver, 2002: Daily maximum and minimum temperature trends in a climate model. Geophys. Res. Lett., 29, 1356, doi:10.1029/2001GL014556.

Streets, D. G., and Coauthors, 2003: An inventory of gaseous and primary aerosol emissions in Asia in the year 2000. J. Geophys. Res., 108, 8809, doi:10.1029/2002JD003093.

Stull, R. B., 1988: An Introduction to Boundary Layer Meteorology. Kluwer Academic, $666 \mathrm{pp}$.

Sun, Y., S. Solomon, A. Dai, and R. W. Portmann, 2007: How often will it rain? J. Climate, 20, 4801-4818.

Trenberth, K. E., 1998: Atmospheric moisture residence times and cycling: Implications for rainfall rates with climate change. Climatic Change, 39, 667-694.

—- A. Dai, R. M. Rasmussen, and D. B. Parsons, 2003: The changing character of precipitation. Bull. Amer. Meteor. Soc., 84, 1205-1217.

Warner, J., and S. Twomey, 1967: Comparison of measurements of cloud droplets and cloud nuclei. J. Atmos. Sci., 24, 702-703.

Yan, Z., and Coauthors, 2002: Trends of extreme temperature in Europe and China based on daily observations. Climatic Change, 53, 355-392.

Zheng, X., R. E. Basher, and C. S. Thompson, 1997: Trend detection methodology for annual time series and its application to maximum, minimum, and mean temperature, diurnal range, and regional SST. J. Climate, 10, 317-326. 